Komissarov, P.V. (2021). Comprehensive assessment of the base of mathematical modelling of production business processes. Actual Issues of Management Development. European Scientific e-Journal, 8 (14), 7-23. Hlučín-Bobrovníky: “Anisiia Tomanek” OSVČ.

Комиссаров, П.В. (2021). Комплексная оценка базы математической моделирования производственных бизнес-процессов. Actual Issues of Management Development. European Scientific eJournal, 8 (14), 7-23. Hlučín-Bobrovníky: “Anisiia Tomanek” OSVČ.

DOI: $10.47451 / \operatorname{man} 2021-09-001$

EOI: 10.11244/man2021-09-001

The paper is published in Crossref, Internet Archive, ICI Copernicus, Google Scholar, Academic Resource Index ResearchBib, JGate, ISI, CiteFactor, eLibrary databases.

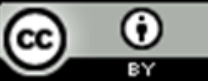

Peter V. Komissarov

$\mathrm{PhD}$ student

Admiral Makarov State University of Maritime and Inland Shipping

St Petersburg, Russia

E-mail: KomissarovP@yandex.ru

\title{
Comprehensive assessment of the base of mathematical modelling of production business processes
}

\section{Abstract:}

The relevance of mathematical modelling lies in finding the correct quantitative characteristics (indicators, parameters) of the effectiveness of the functioning of the process under study, identifying quantitative estimates of the relationships between its elements. Based on the simulation results, the best parameters of the designed equipment and the optimal or rational variant of the production process are selected. The characteristics of the process may vary depending on the purpose. In technological tasks, they are related to the quality of the products and productivity, and the components of any process are usually taken into account simultaneously. The purpose of this study is to analyze various aspects of the use of mathematical modelling in the design of production business processes. In the study course, the mathematical modelling essence was analyzed, the features of the mathematical model development were determined, and the features of mathematical modelling of production business processes were revealed. The author concludes that the mathematical basis for modelling production processes is used at all levels and typologies of business processes starting from micro-processes of task execution or product production to the macro-processes of enterprise management or order (project) implementation. The complexity of using the mathematical base lies in the diversity of business processes and a wide variety of production processes, which requires constant development of numerical methods and algorithms for the correct implementation of the processes themselves and their complex chains.

\section{Keywords:}

mathematical modelling, business processes, mathematical model, risks.

\section{Пётр Вениаминович Комиссаров}


им. адмирала С.О. Макарова

Санкт-Петербург, Россия

E-mail: KomissarovP@yandex.ru

\title{
Компхексная оценка базы математической модемирования производственных бизнес-процессов
}

\begin{abstract}
Aннотачия:
Актуальность математического моделирования заключается в нахождении корректных количественных характеристик (показателей, параметров) эффективности функционирования изучаемого процесса, выявлении количественных оценок взаимосвязей межАу его элементами. На основе результатов моделирования выбирают наилучшие параметры проектируемого оборудования и оптимальный или рациональный вариант производственного процесса. Характеристики изучаемого процесса могут быть различными в зависимости от цели. В технологических задачах они связаны с качеством получаемой продукции и производительностью, а состав яющие Аюбого изучаемого процесса обычно учитываются одновременно. Целью Аанного исследования является анализ различных сторон использования математического моделирования в дизайне производственных бизнес-процессов. В ходе исследования был проведён анализ сущности математического моделирования, определены особенности разработки математической модели и выявлены особенности математического моделирования производственных бизнес-процессов. Автор приходит к заключению, что математическая база моделирования производственных процессов используется на всех уровнях и типологиях бизнеспроцессов, начиная с микропроцессов исполнения задания или производства изделия АО макропроцессов организации управления предприятием или реализации заказа (проекта) и сложность использования математической базы заключается в многообразии бизнеспроцессов и широком разнообразии производственных процессов, в связи с чем требуется постоянная разработка числительных методов и алгоритмов Аля корректной реализации самих процессов и их комплексных цепочек.
\end{abstract}

Ключевые слова:

математическое моделирование, бизнес-процессы, математическая модель, риски.

\section{Introduction}

Economic thought develops in parallel with the social development of society, competing with it in the priority of being a social locomotive. Philosophy still finds it difficult to determine which sphere of human activity is primary and only secondary. Historically, discoveries and inventions are based on human ideas about the nature that surrounds us. However, they are impossible without social changes that provoke or motivate individuals to solve complex technical or scientific issues that are not standard for this time (Buychik, 2021). 
The relevance of mathematical modelling lies in finding the correct quantitative characteristics (indicators, parameters) of the effectiveness of the functioning of the process under study, identifying quantitative estimates of the relationships between its elements. Based on the simulation results, the best parameters of the designed equipment and the optimal or rational variant of the production process are selected. The characteristics of the process under study may vary depending on the purpose. In technological tasks, they are related to the quality of the products and productivity, and the components of any process under study are usually taken into account simultaneously (Hammer \& Champy, 1993). Thus, when studying the method of reaching the break-even point, the productivity of the technological line, the quality of the produced grades and cost characteristics are taken into account. In the example of solving transport problems, productivity comes to the fore, predetermined by the selected scheme of work and the system of machines.

The study purpose is to analyze various aspects to use mathematical modelling in the design of production business processes.

Based on the study purpose, the following objectives were solved:

- $\quad$ analyze the essence of mathematical modelling;

- determine the features of the development of a mathematical model;

- identify the features of mathematical modelling of production business processes.

Comparative, logical methods, synthesis and generalization were used to achieve the tasks set.

In the course of the study, the works of significant researchers in the field of mathematical modelling of business processes A.G. Madera, M. Robson, F. Ullah, M. Hammer, J. Champy, J. Harrington, E. Esseling, H. van Nimwegen, S.G. Powell, M. Schwaninger, J. Sloman, C. Trimble, and others were used.

\section{The essence of mathematical modelling}

The general scheme of the mathematical model can be represented as

$$
E=f(x, y)
$$

There:

$E$ is the result of the functioning of the system or process under study, which is to be determined;

$x$ is controlled variables and parameters of operating factors;

$y$ is unmanaged variables and factors; 
$f$ is the functional relationship between $x$ and $y$, which determines the value of $E$ (Madera, 2009).

Therefore, in general, a mathematical model is a combination of the following components:

- component,

- $\quad$ variable parameters (indicators),

- functional dependencies,

- restrictions,

- target functions.

Components are components that, when combined appropriately, form a system or process. Sometimes components are called subsystems, or system elements. The parameters are selected arbitrarily. The values of variables are determined by this function type. After giving them certain values, the parameters become constant values that cannot be changed.

Functional dependencies characterize the behaviour of variables and parameters within a subsystem or express the relationship between subsystems. Usually, functional dependencies are established based on mathematical analysis methods and hypotheses based on the physical essence of the simulated process.

Constraints set limits on changing the values of variables. They can be set by the developer of the model (artificial limits) or by the system (process) due to its inherent properties (natural limits). So, when modelling the operation of a cutting machines system, the maximum volume of a bundle of trees formed by a fellingpacking machine, the permissible sizes of harvested trees, the capacity of the upper warehouse, etc., can be artificial restrictions. In this case, the maximum volume of harvested wood, predetermined by its stock in the cutting area, the relief of the cutting area, soil and soil conditions, etc., can act as natural restrictions. While natural limits are stable, artificial limits can be modified.

Mathematical modelling includes the following steps:

1. Substantiation of the purpose and statement of the main objectives of the object (process) research.

2. Preliminary study of the object, the allocation of its essential characteristics, the establishment of limitations and indicators of the effectiveness of the process.

3. Selection and, if necessary, correction or development of new theoretical prerequisites for the model being developed.

4. Preparation of the initial information for the initial data of the model and setting up the experiment. 
5. Performing model calculations, analyzing the results obtained and comparing them with the characteristics of a real object.

6. Correction (if necessary) of the developed model.

7. Implementation (practical use) of modelling results, in the form of recommendations, the design of the modelling process in the form of techniques and instructions (Kremer \& Putko, 2002).

The first stage is associated with the continuous refinement of tasks, and the study is accompanied by adjustments, the establishment of assumptions and limitations. When setting the task and determining the type of model, it is necessary to clearly define the physical essence of the process under study and establish the boundaries of its functioning. It is not easy, given that production is a single system. Having justified the purpose, study objectives, and the boundaries of the process under study, researchers determine the factors that must be considered when modelling the process. The main danger, which lies in waiting for a researcher, when a model is building, is that the model tends to overgrow with details and elements that insignificantly increase the adequacy of the results, but complicate, often to the point of destruction, the process model.

Pareto's law states there is a vital minority and a trivial majority in every group or set of factors. The model should fully consider this vital minority, separating itself as much as possible from the insignificant majority of details.

To build a model, it is necessary to reasonably choose quantitative and qualitative initial data. At the same time, it is necessary to decide which data should be obtained experimentally, which can be accepted by analogy with other previously studied processes, and which can be obtained based on theoretical prerequisites. As representative and reliable as the initial information embedded in the model is, the final results of the simulation will be so reliable (Koubarakis \& Plexousakis, 2002).

If the model is calculated on a computer, then the developer faces the problem of describing the problem using methods acceptable for the computer used.

Model verification is one of the most important stages aimed at obtaining an acceptable level of confidence of the developer and user that the calculation results and conclusions obtained based on process modelling will be sufficiently accurate and reliable. Such verification should be especially correct for models of complex structure. In this case, the following methods can be used. First, the experimenter must make sure that the model is right in the first approximation. To do this, the initial data is usually embedded in the model to obtain the maximum values of the result. If such a result is absurd, they look for an error in the model. After making the necessary corrections, the correspondence of the results to the physical essence 
of the simulated process is calculated again. Such a check is effective when the experimenter (model developer) is a specialist in this industry, well versed in the features of the real process. He should understand and explain, e.g., in which direction (smaller or larger) the process parameters should change with a corresponding change in the initial data and, comparing the calculation results, give a preliminary assessment of the reliability of the developed model. The final verification and evaluation of the model are given by practice, production verification of the simulation results. However, such verify is often impossible, for example, when there are no analogues to the modelled process, or it can be carried out only for a part of the results and conclusions. Therefore, the key to successfully solving the problem can be a combination of knowledge of production and an idea of modelling. The opinion that sometimes exists that a mathematician, especially one who knows computer programming methods, can successfully solve production problems, is just as wrong as relying only on the experience and knowledge of production by an engineer.

No modelling task is successfully completed until the correct design and practically verification has been performed. The greatest modelling difficulties are associated with the user's perception of the results and implementation (implementation). So, according to US scientists involved in modelling, the design time of the model is distributed as follows:

$25 \%$ - for the formulation of the problem,

$20 \%$ - for data collection and analysis,

$30 \%$ - for model development,

25\% - for implementation (Masepa, 2014, c).

For the developed model to find application in the analysis and design of processes of other enterprises, materials related to modelling are issued in the form of documents: methodologies, collections of programs, instructions.

Based on the mathematical model of the process, quantitative estimates of parameters and interactions of related operations are determined. The better the mathematical model is chosen, the better it reflects the main features of the process, the more successful the research will be and the more useful the recommendations resulting from it. There are no general ways to build mathematical models. In each specific case, the model is built based on the purposefulness, tasks of analysis and process management, taking into account the accuracy of both the final results and the initial data. In complex cases, it is useful to investigate the same process on several models. If the results change little from model to model, this is a serious argument for the study objectivity. 
Mathematical models, which can be applied in process research tasks, can be conditionally divided into analytical and statistical ones (Komissarov, 2020). The first is characterized by the analytical dependencies establishment between the process parameters written in the form of algebraic formulas, differential equations, etc. With the help of analytical models, it is possible to describe relatively simple processes with satisfactory accuracy.

In complex processes in which the interaction of a huge number of factors, including random ones, is intertwined, it is advisable to model statistical (probabilistic, stochastic, simulation) methods using computers for calculations. The advantage of statistical methods over analytical ones is that they allow taking into account a huge number of factors and do not require gross simplifications. However, the results of statistical modelling are more difficult to analyze than analytical dependencies. The best results are obtained by the combined use of analytical and statistical models: a simple analytical model determines the main regularities of the process, and further refinement, assessment of the impact of unaccounted factors can be obtained by statistical modelling. This complex method is accepted as the main one for modelling logging operations.

It is impossible to copy real objects and processes for sure. Even a relatively simple technological process includes many elements, various relationships between them including numerous constants and variables, constraints, etc. An attempt to include in the developed model all or almost all the factors and relationships that characterize the real process can significantly complicate the model and its solution. At the same time, the desire to simplify the model and calculations can lead to incorrect results. The art of modelling is to find the "golden mean" - to develop a simple model that covers the main features of the real process and provides results of acceptable (specified) accuracy. However, at the same time, it is dangerous to miss the important. Otherwise, such a bad model will inevitably collide with practical verification.

The purpose of the process study determines by plenty of features, more or less significant in the simulated real process, the data and factors, which need to be considered. For example, the importance of factors should be assessed, first of all, by a technologist, designer or designer investigating or designing a process and a machine. If an industry specialist has no idea about the methods and possibilities of modelling, then he will set an incorrect task. For this type of risk to be minimized or eliminated, an industry specialist engineer must have a fairly clear understanding of the methods and capabilities of mathematical modelling. 
The main difficulty to form a model is the need to combine two processes that are opposite in direction: simplification of the model and accuracy of the results. Modelling consists of the ability to analyze the process, isolate the most significant features from it by inference, reasonably exclude non-essential factors from further consideration, and then work out and improve the model until the desired results are obtained.

Simplification of the model is usually achieved by the following operations: excluding some variables or turning them into constants, replacing complex dependencies between variables with linear dependencies if possible, introducing stricter restrictions and boundary conditions.

\section{Features of the mathematical model development}

The development of the model is not limited to a single option. As the goals are achieved, it is possible to adjust the model to ensure its greater compliance with the real process. The corresponding step-by-step complication of the model is justified. It allows you to comprehensively analyze the results, quantify the impact of the main variable factors on the efficiency of the process.

There are no clear rules on how to formulate a problem at the very beginning of its modelling, as well as specific formulas and methods to select variables and constants, functional dependencies, constraints and criteria to evaluate the model effectiveness. A good model must meet the following conditions. It should be simple and understandable to the user, purposeful, guaranteed from absurd answers, sufficiently complete in terms of the possibilities of solving the main tasks, convenient and understandable in handling, allowing its correction and updating (Sloman, 2006).

The languages used for making models can be divided into verbal descriptions, drawings, logical flowcharts and decision tables (or graphs of states), curves, nomograms, mathematical descriptions (equations, formulas and algorithms) (Kleiner, 1986). Each of these languages types has certain characteristics that make it more suitable for use in any specific case. None of these languages types is equally suitable for any purpose. All the modelling languages types are used when analyzing the technological process and solving special tasks. However, general attention is paid to the mathematical description of the process, since this method provides ample opportunities for effective analysis and control of technological processes.

Mathematical modelling, for example, of the timber harvesting process is based on methods of operations research, which have the following arsenal of mathematical tools: probability theory, queuing theory (QT), reliability theory, theory 
of random processes, mathematical statistics, simulation modelling, game theory, Monte Carlo method, linear programming, dynamic programming, network planning, mathematical optimization methods, etc.

Not all mathematical methods are equally applicable to the tasks. The following is a brief description of the modelling languages that are most widely used in solving problems.

1. Verbal description has a good descriptive ability. It is very ambiguous as a language. There is no suitability for manipulation. Usage is limited. The principal purposes are descriptive explanations and instructions.

2. Drawings and diagrams have a good descriptive ability. They are unambiguous as a language. There is no suitability for manipulation. Usage is wide. The principal purpose is the design of the technological process.

3. Logical flowcharts and decision tables have a fairly good descriptive ability. They are very unambiguous as a language. There is no suitability for manipulation. Usage is wide. The principal purpose is computer programming.

4. Curves, tables and nomograms have a fairly good descriptive ability. They are unambiguous as a language. The suitability for manipulation is well. Usage is limited. The principal purpose is to express simple dependencies between several variables.

5. Mathematical description has a weak descriptive ability, uniquely as a language; the suitability for manipulation is very good, the use is wide, the principal purpose is problem-solving and optimization (Khrapov \& Osipov, 2004).

In the structural model of a business process, each individual operation is modelled by the corresponding process link, which receives resource flows $Z=\{X$; $Y\}$, divided into two parts. The flow vector $X=\{1 x, 2 x, \ldots, x n\}$ at the entrance to the $i$-th process link includes flows of material resources or factors of products purchased in the external environment; the flow vector $Y=\{1 y, 2 y, \ldots, y k\}$ includes products produced in the process links preceding the $i$-th link, which are input resources for production in this $i$-th link. The resources belonging to vector $X$ will be called exogenous, the resources included in vector $Y$ is endogenous. In general, resources of both kinds (endogenous and exogenous) are fed to the input of each process link (Kiselev et al., 2014).

In the structural model of the business process, the flows of exogenous and endogenous resources are indicated by circles, process production links by rectangles, service links by rhombuses, the flow of resources and/or products by arrows (Fig. 1). So, for example, the structural model of a business process contains the first service link and four production links 2, 3, 4, 5. Exogenous resources of $1 x$, 
$2 x, 3 x, 4 x, 5 x$ are received (purchased) from the external environment. Product streams $1 y, 2 y, 3 y$ produced in process links 2, 3, 4 are endogenous since they simultaneously arrive as resources for the following process links, stream $4 y$ represents the produced final product, which is the ultimate goal of the entire business process. The material flows of resources $1 x, 2 x$ at the input and output of the first service link are equal to each other, since, as will be shown below, they do not undergo changes in the process of performing service work on them.

Depending on the activity type carried out, process links can be attributed to production or service links. In the production link, there is a transformation of material resources (factors of production) coming to the input of the link into a product at its output (intermediate, semi-finished, work in progress, final) and at the same time - the transformation of the value of incoming factors into a new added value of the product at the output of the link. Unlike the production links, the product is not produced in the service or maintenance link, the material factors of production are not spent, but when performing service (maintenance) work, a value is added proportional to the costs of their implementation and transferred to the final product of production. Service works include, for example, cargo processing, transportation, warehousing, storage, etc. (Komissarov, 2021)

The production function can serve as a mathematical model of the production operation for processing resources performed in the production link at the input of the link to the product at the output (Kleiner, 1986). For process link $i$ with exogenous and endogenous resources at the input and one product produced in the first link at the output (Fig. 2), the mathematical model is a multifactorial production function:

$$
y_{i}=f_{i}\left(x_{1}, \ldots, x_{n} ; y_{1}, \ldots, y_{k}\right) .
$$

Simultaneously with the physical transformation of the material factors of production in the production link, the cost of the input stream is transformed into the cost of the output stream (Sloman, 2006). As a result, a stream with a value exceeding the value of the resource flow at its input by an amount equal to the added value produced in the link is obtained at the output of the link, which is a function of the flow volume $y_{i}$ at the output of the link and has the form of a U-shaped curve with a pronounced minimum (Sloman, 2006).

Along with the production links in the business process, there are also service links (Fig. 3) in which the maintenance of the material flow is realized. Unlike production, in the provision of services, the processing of factors into qualitatively new products is not carried out. As a result, there is no special purchase of resources intended for processing into products. Service activity deals with already produced 
products (final product, semi-finished products, work in progress, production factors); it is realized in the form of value-added when performing service work on it, as opposed to value-added due to the production processing of factors into a new product. Service types of work include, for example, transportation, packaging, warehousing, storage, loading / unloading, consolidation, registration of accompanying documentation, etc.

The following features characterize the mathematical model of the service link:

1) the volumes of input and output material exogenous and endogenous flows in the service link are equal to each other and do not change when performing service operations;

2) when carrying out service work on products, the added costs per unit volume of the output product are added to the costs of each element of the input stream, which are, in general, functions of the material flows' volume at the output of the service link (Fig. 3).

Each process link performs some operation (work), which is part of the full cycle of production and/or service of the final product. As already noted, there is a fundamental difference between production and service process links, which consists of the fact that production processes are oriented to the future volume of demand and supply of the final product produced, and service processes are oriented to the maintenance of already produced products (completed or incomplete), the volume of service of which is determined by the contract between the owners of the production and service process. Therefore, approaches to the design of production and service business processes differ significantly from each other. While designing production processes, the main principle is to satisfy the projected supply and demand for future products. While designing service processes, it is necessary to be guided by the quality of customer service, in the volumes of finished products that come from the customer of service work, that is, the owner of the business process.

\section{Features of mathematical modeling of production business processes}

The design, modelling and optimization of the business process are carried out from the output of the business process to its input and are of an optimization nature. This is because to decide the optimal volumes to purchase production factors, to produce intermediate and final products in process units, it is necessary to have a forecast of the volume of future demand and the future price of the product planned for release (Harrington et al., 2002). Demand and prices for factors of production and future products are uncertain and a priori unknown. It is due to the uncertainty of updating in the future the state of the economy, finance in which the business 
process is carried out, the volume of supply taking into account the competitiveness of the future product, the state of organizations involved in the business process (organizational, financial, management, etc.).

All significant predictive characteristics, which the business process owner is guided by when deciding on its initiation, in the future, are associated with the actualization of various kinds of events, which, if favourable for the business process, are chances, otherwise risks (Madera, 2014, b). Therefore, when optimizing process design, the most relevant criterion should reflect the possible actualization of both chances and risks, as well as the ratio between them in the future. Such a relevant (maximized) criterion is the complex criterion of chance and risks (R\&Ch) (Madera, 2014, b), equal to:

There:

$$
R \& C h=\beta_{C h} C h-\beta_{R} / R /
$$

Ch и $\mathrm{R}$ are the full predicted chance and risks relevant to the business process in question;

$\beta_{C b} \geq 0$ and $\beta_{R} \geq 0$ are the ratio of relative importance of chance and risks from the point of view of the owner of the business process.

According to the R\&Ch odds and risks criterion, the best solution's selection is based on maximizing chances while minimizing risks, which reflects the psychology of decision-making by the subject. Indeed, when deciding to start a new project, the subject is guided, first of all, by those new opportunities and "rosy" prospects that promise it the results of the project in the future, i.e., changes, and only secondarily it takes into account possible difficulties and obstacles, that is, risks that it may face on its way (Vergidis \& Tiwari, 2008). In other words, the chance is a motivation for action, and risks are a manifestation of caution when choosing a specific way to implement your plan. "It is our innate thirst for the activity that is the force that moves the world" (Keynes, 2012). Making decisions based only on the analysis of risks alone (as is the case in the existing literature) is the choice of the least from the set of the greatest ones. It says nothing about how much it is advisable to start this or that activity at all and what benefits it can bring comparing other options to apply efforts and invest. Moreover, the answer to the last question can be obtained in the process of analyzing the chances only.

The values of chances $C h$ and risks $R$ of any activity, including process, are defined as the sum of the products of material measures of chances (income, profits) $M_{C h, k}(k=1,2, \ldots, L)$ and risks (losses, losses) $M_{R, k}(k=1,2, \ldots, \mathrm{K})$ - on measures of their possible actualization $P_{C b, k}$ and $P_{R, k}$. In the future, only one event out of the set of possible $L$ chances and $K$ risks can be actualized, so they form a complete group 
of events. The total chances $C h$ and risks $R$ are calculated according to the expressions (Madera, 2014, c):

$$
C h=\sum_{k=0}^{L} M_{C h, k} P_{C h, k} R=\sum_{k=1}^{L} M_{R, k} P_{R, k}
$$

The optimization mathematical model of the production business process has the following form:

$$
R \& C h=\beta_{C h} \sum_{k=0}^{L} M_{C h, k} P_{C h, k}-\beta_{R} / \sum_{k=0}^{K} M_{R, k} P_{R, k} / \rightarrow \max
$$

When searching for the volume of factors of production $x_{1}, x_{2}, \ldots, x_{m}\left(x_{i} \geq 0, i\right.$ $=1 \ldots m)$ purchased in the external environment to ensure production throughout the business process, at prices $c_{1}, c_{2}, \ldots, c_{m}$, delivering the maximum value to the complex criterion of chances-risks $(\mathrm{R} \& \mathrm{Cb})$ and satisfying the probabilistic financial condition - the probability that the future total costs of purchasing factors of production will not exceed the financial means $I$, will not be less than the value $p$ :

$$
P=\left\{c_{1} x_{1}+c_{2} x_{2}+\cdots+c_{m} x_{m} \leq I\right\} \geq p
$$

The probabilistic budget constraint is due to the fact that future prices for factors of production $c 1, c 2, \ldots, c_{m}$ and the future solvency level of financial resources, or investments $I$, are uncertain and may undergo significant changes in one direction or another in the future. Therefore, the budget constraint can only be understood in a probabilistic sense. Note that the probability of fulfilling the condition $P\{\cdot\} \geq p$ is a subjective probability reflecting the degree of conviction of the owner (expert) of the business process in his forecast, since any economic and social factor, the future actualization of which is subject to forecasting, is not an objective probabilistic object (Keynes, 1921).

The methodology for optimizing the business process under conditions of uncertainty is based on a preliminary forecast of uncertain factors that may be updated in the future:

- $\quad$ state of the economy;

- demand for the final product;

- the volume of the possible offer; the selling price of the produced product;

- $\quad$ prices for the factors of production used;

- the state of the organizational units involved in the business process (financial, organizational, management, etc.) (Harrington et al., 2002).

Mathematical modelling and optimization of the business process for the production and maintenance of a new product scheduled for release include the following stages: 
Stage 1. Optimization of the volume of output of the final product and the volume of factors of production for the current market situation.

Stage 2. Forecast of the future state of the economy, finance, chances and risks and their assessment.

Stage 3. Optimization mathematical model of a business process under predictable future conditions. The optimization mathematical model of the business process (3), (4) describes the optimal volumes of the final product and the costs of production factors while weighing (with coefficients $\beta_{C b} \geq 1, \beta_{R} \leq 1$ ) a favourable forecast of the development of events with a probability of chance $P_{C b, k}$ and an unfavourable forecast with a probability of risk $P_{R, k}$ relative to market conditions at the moment. According to the data found, optimal products are also found at the output of each intermediate process link separately (Hofacker \& Vetschera, 2001).

Stage 4. Determination of average costs and added costs per unit volume in each link.

\section{Discussion}

Within the study framework, it was revealed that a deeper study of the mathematical modelling influence on the formation of the business processes headset is required because there are plenty of variations due to the variety of production processes. Mathematical modelling should not control the optimization of business processes. Therefore, it is necessary to have a clear understanding of the limit of its use for the correct description of business processes both in production and in-office structures.

\section{Conclusion}

Thus, mathematical modelling and optimization of production business processes are important components of the functioning of the enterprise. The mathematical basis for modelling production processes is used at all levels and the typology of business processes, starting from the micro-processes of task execution or product production to the macro-processes of enterprise management organization or order (project) implementation. The complexity of using the mathematical base lies in the variety of business processes and a wide variety of production processes, which requires constant development of numerical methods and algorithms for the correct implementation of the processes themselves and their complex chains. 


\section{References:}

Buychik, A. (2021). Updating the parameters of the development of effective economic thought in order to motivate society to finance innovative activities. Economy at the crossroads of time. European Scientific e-Journal, 4 (10), 7-16. HlučínBobrovníky: "Anisiia Tomanek" OSVČ.

Butsenko, E.V., \& Shorikov, A.F. (2015). Implementation of network economic and mathematical modeling for the business planning process. Economic and mathematical models. Bulletin of UrFU. The series "Economics and Management", 6 (14), 935-953. (in Russian)

Hammer, M., \& Champy, J. (1993). Re-engineering the Corporation: A Manifesto for Business Revolution. London: Nicholas Brealey Publishing.

Harrington, J. (1991). Business Process Improvement. New York: McGraw Hill.

Harrington, J., Esseling, E., \& Nimwegen, H. van (2002). Optimization of business processes. Documentation, analysis, Management, optimization. St Petersburg: ABC. (in Russian)

Hofacker, I., \& Vetschera, R. (2001). Algorithmical approachs to business process design. Computer \& Operations Research, 28, 1253-1275.

Keynes, J.M. (2012). The General Theory of Employment, Interest and Money. Moscow: Helios ARV. (in Russian)

Keynes, J.M. (1921). Treatise on Probability. MacMillan \& Co: London.

Kleiner, G.B. (1986). Production functions: Theory, methods, application. Moscow: Finance and Statistics. (in Russian)

Kremer, N.Sh. \& Putko, B.A. (2002). Econometrics: Textbook for universities. Moscow: UNITY. (in Russian)

Kiselev, D.Y., Kiselev, Y.V., \& Makariev V.D. (Comp.) (2014). Structural analysis of data flows (Data Flow Diagrams - DFD): guidelines. Samara: SSAU Publishing House. (in Russian)

Komissarov, P.V. (2018, a). Actual issues of modelling production processes of complex technical and social and economic systems. Collection of works of the GUMRF, 67-71. St Petersburg: GUMRF. (in Russian)

Komissarov, P.V. (2021). Determination of the centric rate of the economic stability domain for manufacturing enterprises. Economy at the crossroads of time. European Scientific e-Journal, 4 (10), 28-37. Hlučín-Bobrovníky: "Anisiia Tomanek" OSVČ.

Komissarov, P.V. (2018, b). Method of complex assessment of economic indicators of the enterprise. Collection: Analysis and forecasting of management systems in industry and transport, 57-58. St Petersburg: Astra. (in Russian) 
Komissarov, P.V. (2020). Relevance of the application of the theory of fuzzy sets in the calculation of the strategic security of a complex technical system. Actual issues of modern science. Collection of Scientific Articles. European Scientific e-Journal, 6, 2, 55-64. Hlučín-Bobrovníky: “Anisiia Tomanek” OSVČ.

Koubarakis, M., \& Plexousakis, D. (2002). A formal framework for business process modelling and design. Int Syst, 27, 299-319.

Khrapov, V.N., \& Osipov, A.L. (2004). Econometrics. SibAGS Publishing House. (in Russian)

Madera, A.G. (2015). Mathematical modeling and optimization of business processes based on the complex criterion "chances-risks". Russian Manager's Journal, 4 (13), 51-68. (in Russian)

Madera, A.G. (2009). Modeling and decision-making in management. Moscow: LKI Publishing House. (in Russian)

Madera, A.G. (2014, a). Interval stochastic uncertainty of estimates in multi-criteria decision-making problems. Artificial Intelligence and Decision-Making, 3, 105-115. (in Russian)

Madera, A.G. (2014, b). Risks and chances: uncertainty, forecasting and evaluation. Moscow: KRASAND Publishing House. (in Russian)

Madera, A.G. (2014, c). Risks and chances: decision-making in an uncertain future. Management in Russia and Abroad, 2, 12-22. (in Russian)

Nureev, R.M. (2016). “The General Theory of Employment, Interest and Money” J. M. Keynes: Background, Methodology and Specific Interpretations. Journal of Institutional Studies, 1 (8), 6-35.

Powell, S.G., Schwaninger, M., \& Trimble, C. (2001). Measurement and control of business processes. Syst. Dyn. Rev, 17, 1, 63-91.

Robson, M. \& Ullah, F. (2003). Business process reengineering. Moscow: Unity Publishing House. (in Russian)

Sakhabiev, V.A. (2019). Mathematical and instrumental methods of analysis, improvement and management of business processes: studies. stipend. Samara: Samara University Publishing House. (in Russian)

Sloman, J. (2006). Fundamentals of economics. Moscow: Prospect Publishing House. (in Russian)

Tsukanova, O.A. (2015). Methodology and tools for modeling business processes: a textbook. $\mathrm{t}$ Petersburg: ITMO University. (in Russian)

Vergidis, K., \& Tiwari, A. (2008). Business process analysis and optimization: beyond reengineering. IEEE Transactions on Systems, Man, Cybernatics. Part C: Application and Reviews, 1-14. 


\section{Appendix}

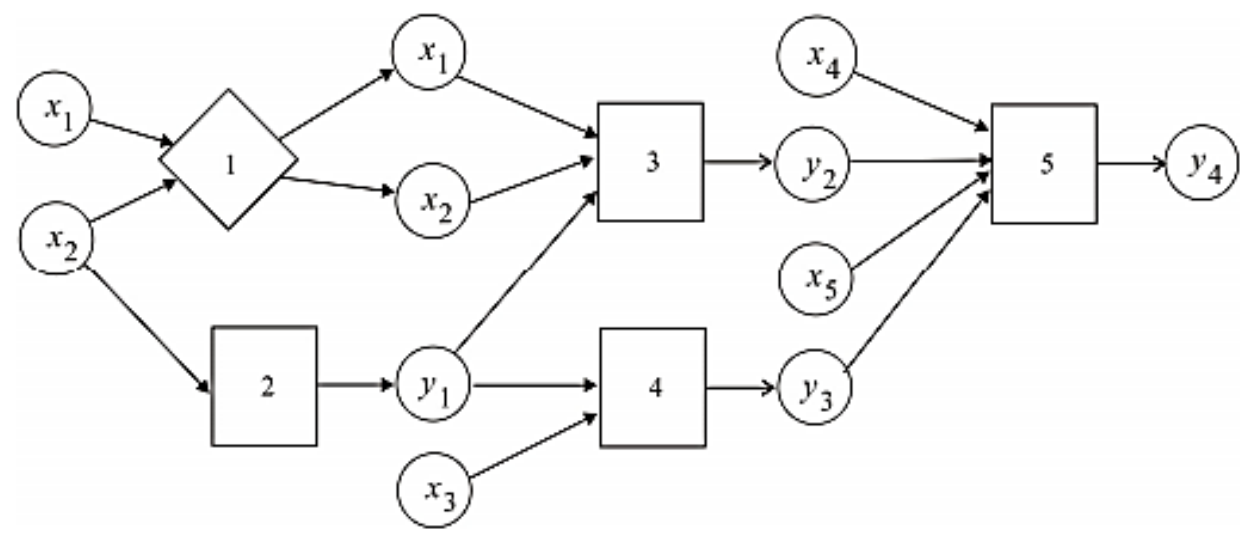

Figure 1. An example of a structural business process model

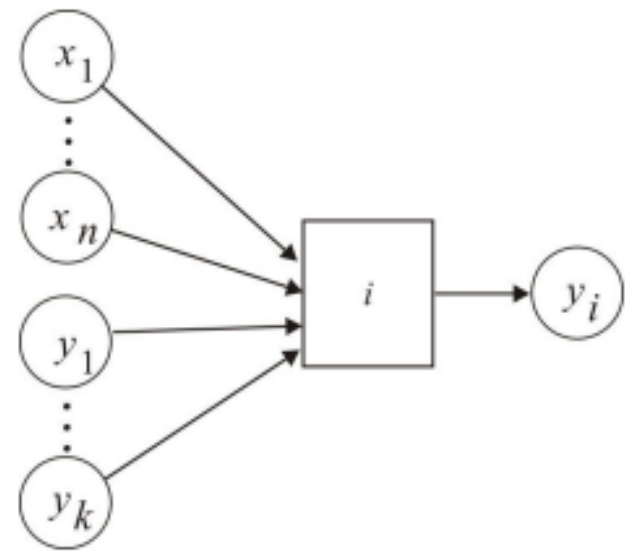

Figure 2. Structural model of the process production link

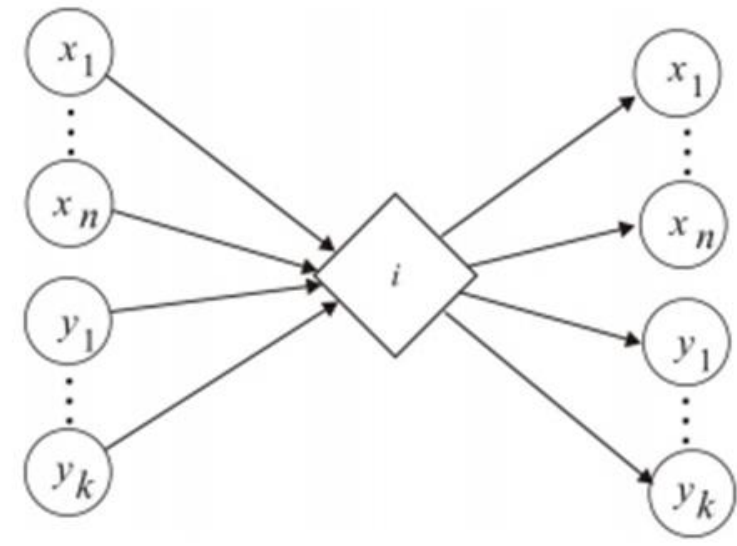

Figure 3. Structural model of the service link 